\title{
An optimal lithium ion battery for plug-in hybrid electric recreational boat in discharging condition
}

\author{
J.S. Norbakyah, C.H. Fung, W.H. Atiq, M.Z. Daud and A.R. Salisa* \\ School of Ocean Engineering, Universiti Malaysia Terengganu, 21030 Kuala \\ Terengganu, Terengganu, Malaysia , Phone: +6096683447; Fax: +6096683991 \\ "Email: salisa@umt.edu.my
}

\begin{abstract}
Plug-in Hybrid Electric Recreactional Boat (PHERB) is a new innovation of conventional boat for water transportation. In the PHERB powertrain, the main power source to drive the boat is the electric machine (EM). The primary energy source of EM is the battery. Battery is an important power energy supplier to PHERB and has two main conditions such as charging and discharging conditions. In this paper, the optimal design of the battery in a discharging condition is reported. The battery model is developed in MATLAB/Simulink environment together with a closed-loop feedback PI controller. By using a power demand curve as a reference for the model, the optimal performance of the discharging battery is obtained by using the genetic algorithm optimization. The results of optimal control parameters of the system are compared with the trial-and-error method. It has been found that the proposed optimal system design can improve the discharged battery's performance significantly.
\end{abstract}

Keywords: Discharging lithium ion battery, PHERB, PI controller, GA optimization.

\section{INTRODUCTION}

Energy, pollution issues, and increasing fuel price have become major problems nowadays $][1,2]$. Thus, the revolution of electric vehicles was introduced. Plug-in hybrid electric vehicles (PHEVs) provide higher fuel efficiency and lower emissions through the combination of the conventional internal combustion engine (ICE) with electric machines (EM) and energy system storage (ESS) [3]. Therefore, the new innovation from conventional boat, namely the Plug-in Hybrid Electric Recreactional Boat (PHERB), was introduced [4].

In the PHERB powertrain, the main power source to drive the boat is the electric machine (EM). The battery pack to supply continuous power to the boat is the primary energy source of EM, and the secondary energy source is the ultracapacitor pack, which is used to absorb the power pulses during regenerative braking and to deliver power for peak acceleration. ICE is set as a backup power source where it is operated under certain conditions and will not be switched on all the time in order to minimize fuel consumption and harmful emissions. The size of ICE can be reduced since its power is needed only when the battery's state of charge (SOC) level is low and to provide required extra torque to assist EM in order to operate the boat during high torque drive conditions [5-9]. A schematic illustration of the proposed series-parallel PHERB powertrain is shown in Figure 1. 


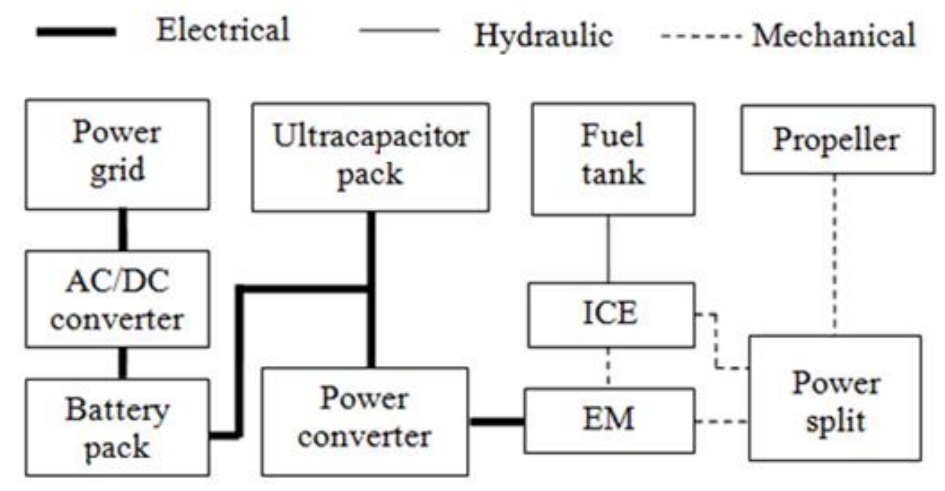

Figure 1. A schematic illustration of the PHERB powertrain [10].

PHEVs are designed using a lithium-ion battery powered for the energy storage system that offers high densities of capacity and power, low memory effect, long life span, high terminal voltage, and low discharge rate as compared with other batteries [1113]. However, lithium-ion batteries are costly and need an optimal charging and discharging system [14], and also require protection from overcharging and overdischarging. This paper presents an optimization method using the heuristic optimization approach of Genetic Algorithm (GA) optimization in order to improve the battery performance of PHERB when running in the battery discharging condition. The battery model developed was based on the saft rechargable litium ion battery, while the control of the battery has been constructed based on the conventional PI control method. With the help of the optimization algorithm of GA, the optimal tuning of the control parameters has been carried out in MATLAB/Simulink environment. The results of the model development and verification as well as the performance of the proposed system have been compared with the conventional trial-and-error method.

\section{METHODS AND MATERIALS}

The research methodology is based on three phases, which are mathemathic modelling in MATLAB/Simulink, PI controller model, and optimization. Li-ion battery was chosen since it offers more advantages as compared to other battery types. It has no memory effect, low self-discharge, high recharging energy efficiency, and has good hightemperature performance [15]. The Li-ion battery can efficiently fill the limited space of the device that they power due to the fact that it can be formed into a wide variety of sizes and shapes. The parameter and specification of the Li-ion battery are presented in Table 1.

Table 1. Parameter and specification of the Li-ion battery model.

\begin{tabular}{lc}
\hline Battery & MP 176065 Saft Lithium-ion \\
\hline Nominal voltage & $3.75 \mathrm{~V}$ \\
Typical capacity & $6.8 \mathrm{Ah}$ \\
Nominal energy & $26 \mathrm{Wh}$ \\
Maximum continous discharge current & $14 \mathrm{~A}(\sim 2 \mathrm{C}$ rate $)$ \\
Pulse discharge current & up to $30 \mathrm{~A}(\sim 4 \mathrm{C}$ rate $)$ \\
Typical weight & $143 \mathrm{~g}$ \\
Volume & $68 \mathrm{~cm}^{3}$ \\
\hline
\end{tabular}




\section{Mathematic Modelling of the Battery}

Once the parameters and specifications of the battery is determined, the model of the system component is developed in MATLAB/Simulink. The Li-ion battery model was built based on the mathematical formula. The battery model was derived based on the equation of the battery itself. Current was applied to the battery when there was a pulse discharge. Ohmic resistance causes immediate vertical voltage drop, while polarization resistance causes exponential voltage drop [16]. The related equations of discharging are as shown below:

$$
E_{d i s}=E_{0}-K \frac{Q}{Q-Q} t i^{*}-K \frac{Q}{Q-Q t}+A e^{-B Q t}
$$

where, $E$ is the no load voltage, $E_{0}$ is the battery constant voltage, $K$ is the polarization constant, $Q$ is the maximum battery capacity, $Q t$ is the extracted capacity, $i^{*}$ is the low frequency current dynamics, $A$ is the exponential voltage, $B$ is the exponential current, $i$ is the battery current, and $R$ is the internal resistance.

The exponential part of Equation (1) is as calculated as in Equations (2) and (3). The "typical discharge characteristic" curve, which is included in the battery datasheet, provides the necessary points used to extract the model parameters. The points include the fully charged voltage, the end of the exponential zone and the end of the nominal zone. In the case of internal resistance not provided in the datasheet, an initial estimate from other Li-ion batteries of similar ratings is made. The internal resistance is assumed to be $0.05 \Omega$.

$$
\begin{aligned}
& A=V_{\text {full }}-V_{\text {exp }} \\
& B=\frac{3}{Q \exp }
\end{aligned}
$$

where, $V_{\text {full }}$ is the fully charged voltage, $V_{\text {exp }}$ is the exponential point voltage, and $Q_{\text {exp }}$ is the exponential point capacity. The polarization voltage, $K$, can be obtained from the fully charged voltage and the third point of the "typical discharge characteristic" curve. The equation of $K$ is shown in Equation 4. On the other hand, the battery voltage constant, $E_{0}$, is shown in Equation 5, where it can be deduced from the fully charged voltage. The variable $i$ is the battery current in Ampere and $\mathrm{R}$ is the internal resistance in ohm.

$$
\begin{gathered}
K=\frac{\left(V_{\text {full }}-V_{\text {nom }}+A\left(e^{(-B Q n o m)}-1\right)\right) \times\left(Q-Q_{\text {nom }}\right)}{Q_{\text {nom }}} \\
E o=V_{f u l l}+K+i R-A
\end{gathered}
$$

where, $V_{\text {nom }}$ is the nominal voltage and $Q_{\text {nom }}$ is the nominal capacity. The discharging power can be determined by the battery terminal voltage and the discharging loss. Equations 6 and 7 show the battery terminal voltage and the discharging loss, respectively. The converter efficiency was up to $98.5 \%$ and was used to calculate the converter loss [9]. However, Equation 8 shows the discharging power of the battery.

$$
\begin{gathered}
V_{\text {batt }}=E-i R \\
P_{\text {loss,discharge }}=\mathrm{V}_{\text {batt }} \times i \times 1.5 \% \\
P_{\text {discharge }}=V_{\text {batt }} \times i-P_{\text {loss }, \text { discharge }}
\end{gathered}
$$


where, $V_{\text {batt }}$ is the battery terminal voltage, $P_{\text {loss,ischarge }}$ is the discharging loss, and $P_{\text {discharge }}$ is the discharging power. From the mathematical equations presented in Equation 1 to Equation 8, the model has been implemented in MATLAB/Simulink.

\section{PI Controller Model}

The PI controller is universally well-known for closed-loop control, which is flexible in terms of operation and ease of tuning. This controller is applied to stabilize the output of the process system with minimal errors for any change of the process system behaviour [17]. Equation (9) in the discrete form and Equation (10) in the z-transform define the model characteristics of the PI controller for digital implementation [18].

$$
\begin{gathered}
\mathrm{U}_{k}=K_{P} \times e_{k}+K_{i} \sum_{i=1}^{k} e_{i}=K_{p} \times e_{k}+K_{I}\left(U_{k}-1+\frac{e_{k}+e_{k}-1}{2} T_{S}\right) \\
\mathrm{U}_{z}=K_{P} \times e_{z}+K_{i} \frac{(z+1) T_{S}}{2(z-1)} E_{z}=\left(\frac{\left(K_{p}+K_{i} \frac{T s}{2}\right) z-K_{p}+K_{i} \frac{T s}{2}}{z-1}\right) E_{z}
\end{gathered}
$$

where $u$ is the control input to process plant; $K p$ and $K i$ are the proportional and integral gains, respectively; $e$ is the tracking error, which is the difference between the desired and actual values; $T s$ is the sample rate; and $U$ and $E$ are the parameters in the z-transform corresponding to $u$ and $e$, respectively. Figure 2 shows the block diagram of the system with PI controller.

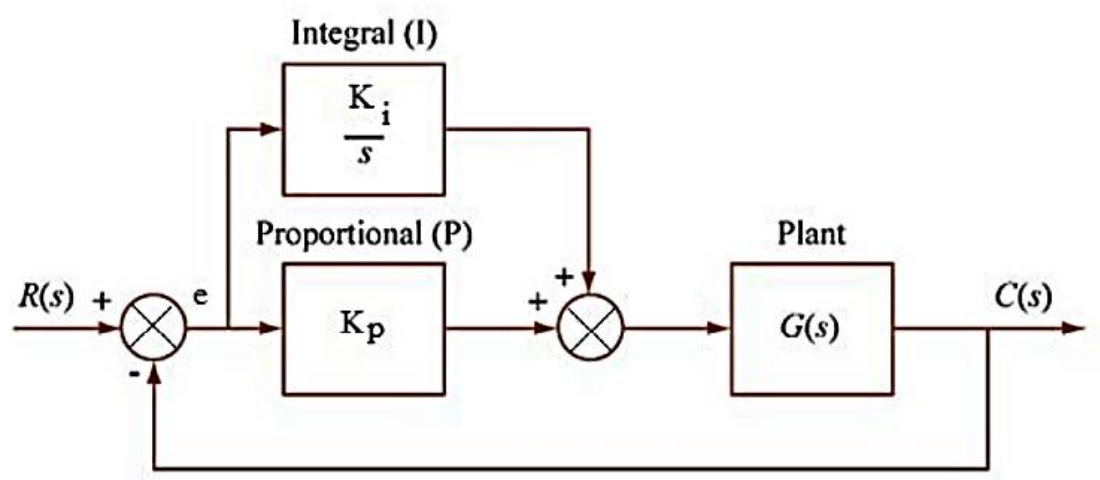

Figure 2. Block diagram of system with PI controller.

\section{Genetic Algorithm Optimization}

For the optimization stage, the Genetic Algorithm (GA) method was chosen. The implementation of PI controller in the closed-loop system is as shown in Figure 3. GA was used to minimize the error signals of the closed-loop control system. In process control applications, PI controller the most commonly used due to the ease of operation and satisfied performances. By adjusting the proportion gain $(K p)$ and integral gain $(K i)$, the dynamic properties of the controller can be modified. $K p$ has the effect to reduce the rise time, but never eliminate the steady state error [19]. However, there was an improvement on the steady state error by controlling $K i$. The initial population of the PI parameters was chosen based on the trial-and-error method. The simulation for controller response to unit step is as shown in Figure 4. It was used as a recommendation for choosing the lower bound and upper bound of $K p$ and $K i$. 


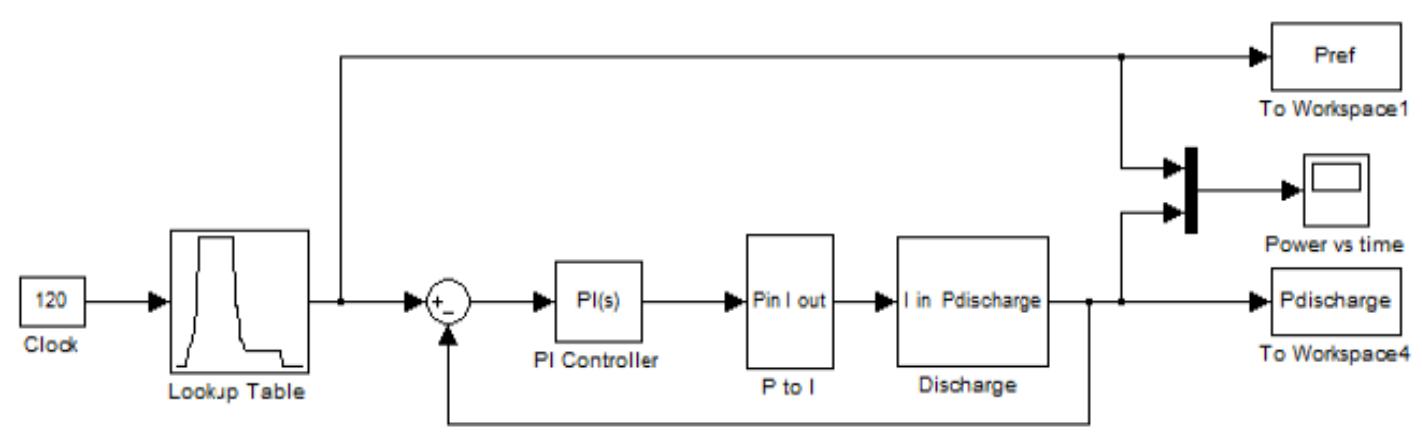

Figure 3. Closed-loop system for GA optimization.

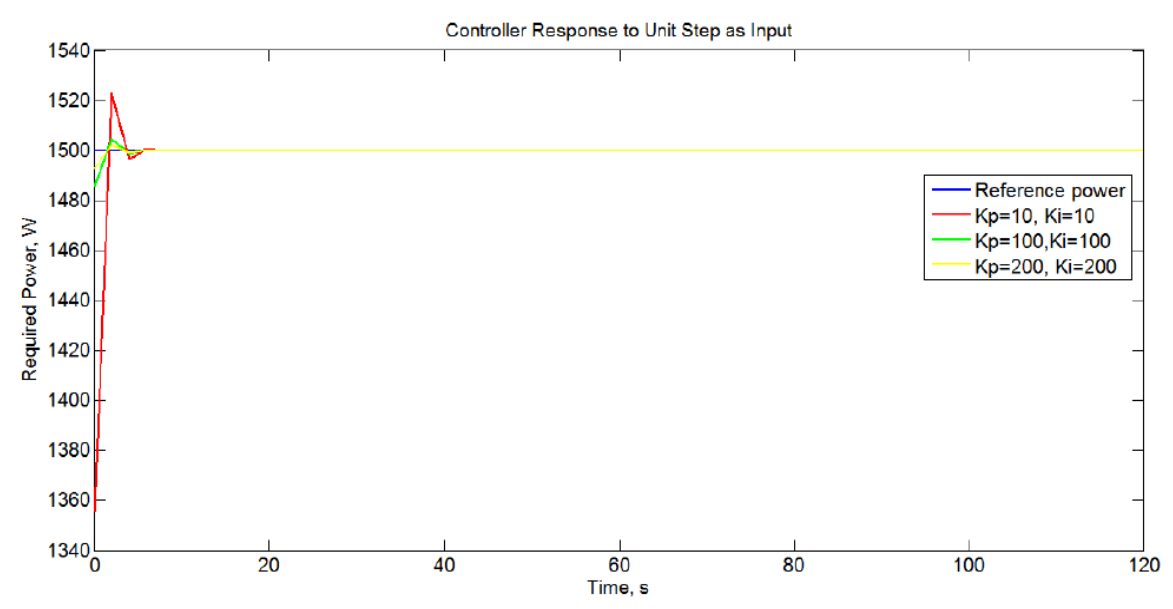

Figure 4. Controller response to unit step.

From the controller response to unit step, obviously, $K p$ and $K i$ equal to 10 were not chosen because of their higher overshoot, rise time, and settling time [19]. Therefore, the ranges were not taken into account for optimization with GA. When both $K p$ and $K i$ equal to 100 and 200, they have lower overshoot, rise time, and settling time as compared to $K p$ and $K i$ equal to 10 . Hence, the range above 100 was chosen for better performance on the optimization. When tuning the PI controller using GA, in the Simulink model, the parameters of GA were initialized. 80 chromosomes in one population were chosen because the bigger the chromosome number, the better the chance to obtain the optimal result. The selection method determines how individuals are selected for mating. In this research, the Roulette Wheel Selection method was chosen because it allows the weaker chromosomes to be selected many times. However, crossover was operated by swapping certain parts of the two selected strings in a bid to obtain the good parts of old chromosomes. Hence, this creates better new chromosomes. The selected crossover probability was 0.95 . For mutation, it is the occasional random alteration of a value of a string position. The high mutation rate would destroy fit strings and degenerate GA into a random search, therefore, it was set to a low rate at 0.085 [10]. The selected maximum number of generations was 100 in order to terminate the continuous evolution procedure. For fitness function, Integral of Time Multiply by Absolute Error (ITAE) was chosen. Figure 5 shows the flow chart of the GA process, which is used in an attempt to overcome the other conventional approaches in nonlinear cases [20]. 


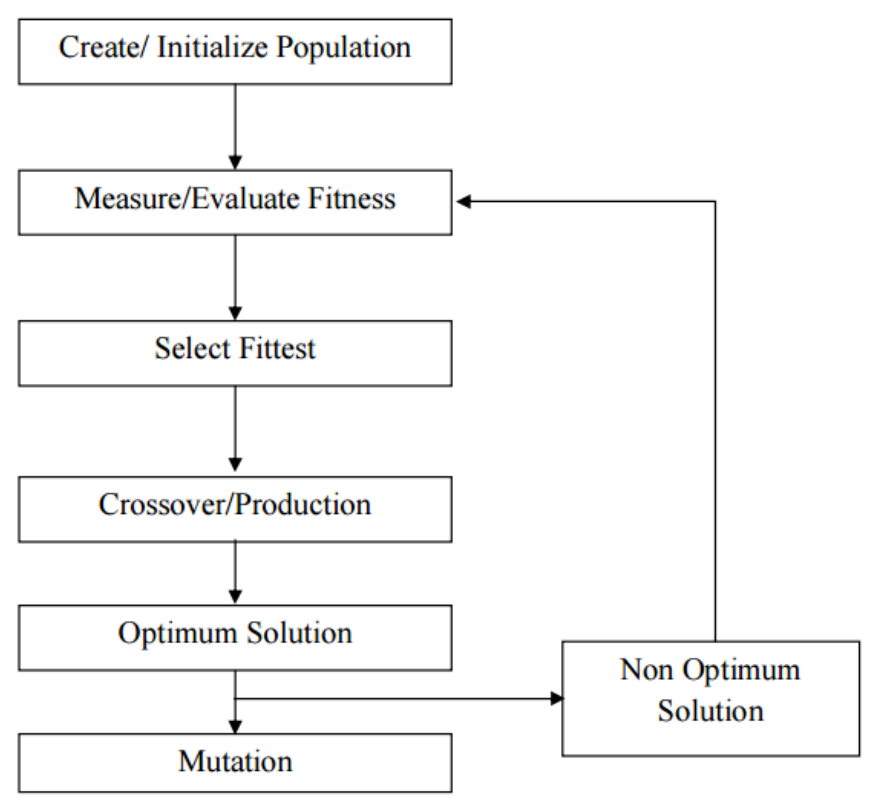

Figure 5. General flowchart for GA.

\section{RESULTS AND DISCUSSION}

The block parameters in MATLAB/Simulink were set up before running the simulation. The parameters of each block used were set based on the specification and datasheet. The simulation of the characteristics of the Li-ion battery was done and the results were discussed.

\section{Model in MATLAB/Simulink}

The discharge model was constructed in MATLAB/Simulink with the corresponding input and output variables representing the battery model as shown in Figure 6.

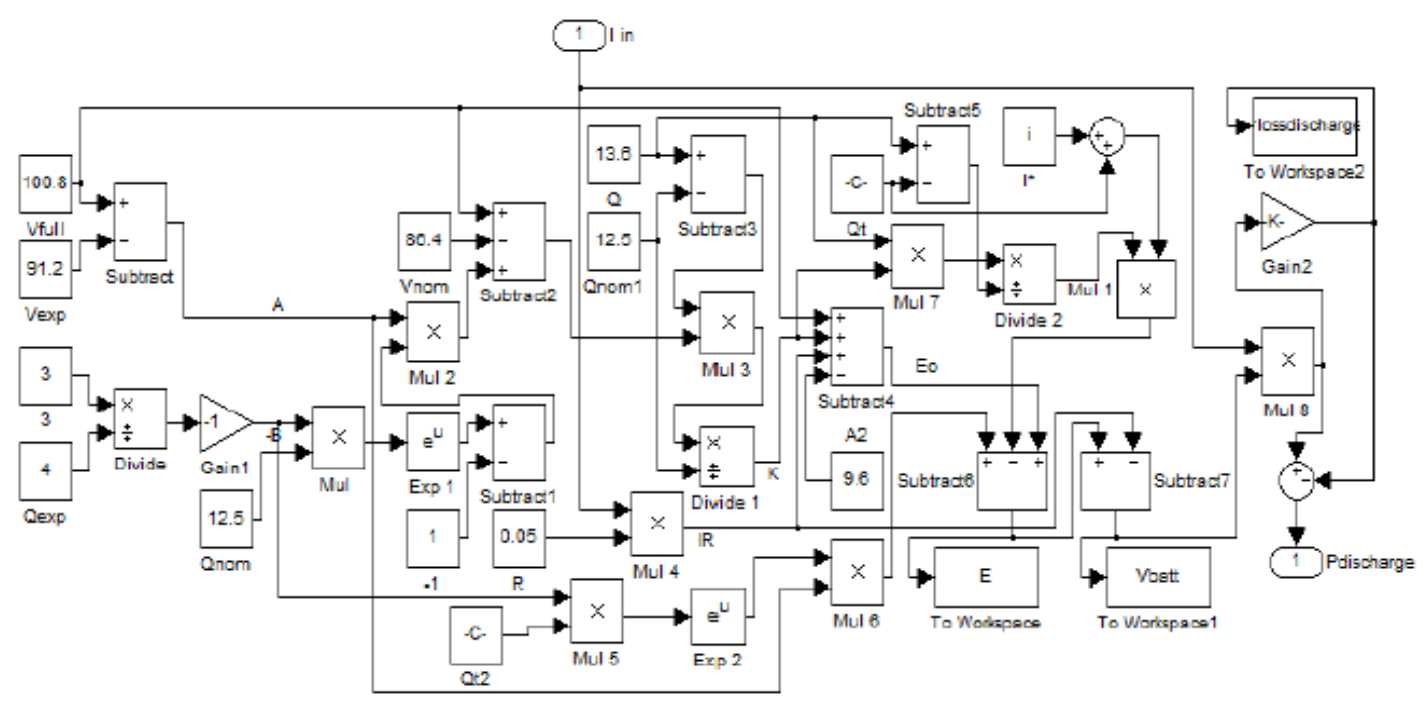

Figure 6. Discharge battery model. 
The typical discharge profile of the Li-ion battery under different C-rates is shown in Figure 7. The result of open circuit voltage versus capacity was conducted for 1C, 2C, and $5 \mathrm{C}$ discharges to identify the rate capacity effect of battery. The traits were the same as the nominal current discharge characteristics and can be validated and the patterns are similar [21] as in Figure 8. The curve showed the two zones of the discharge characteristic, namely exponential zone and nominal zone. The C-rate is a measure of the rate at which the current is used to discharge the battery. An $1 \mathrm{C}$ rate means that the discharge current will discharge the entire battery in one hour. The higher the C-rate, the shorter the discharge period.

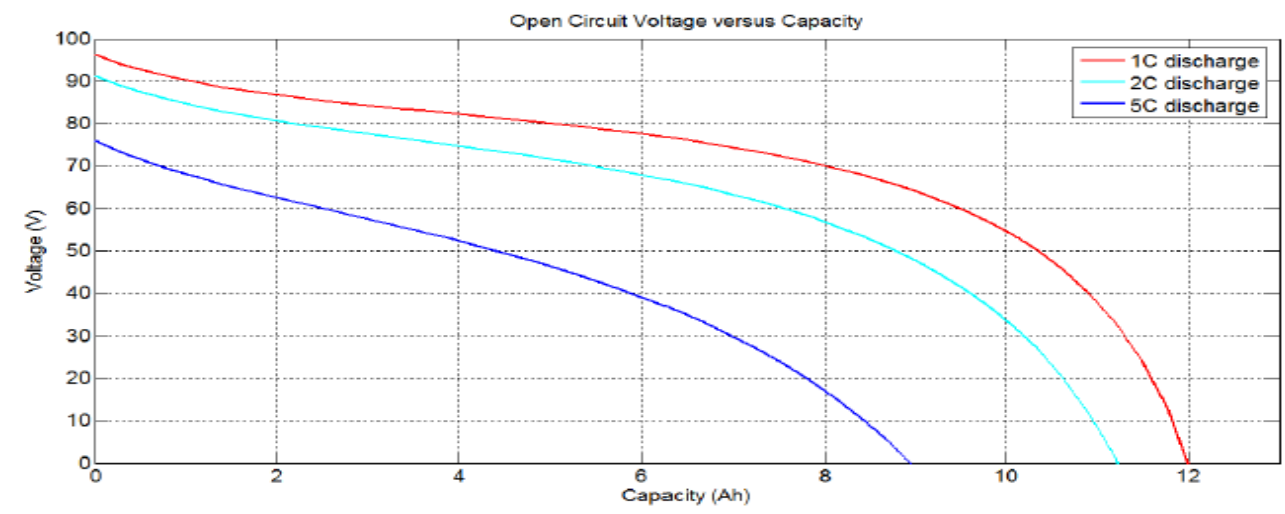

Figure 7. Open circuit voltage versus capacity in discharge condition.

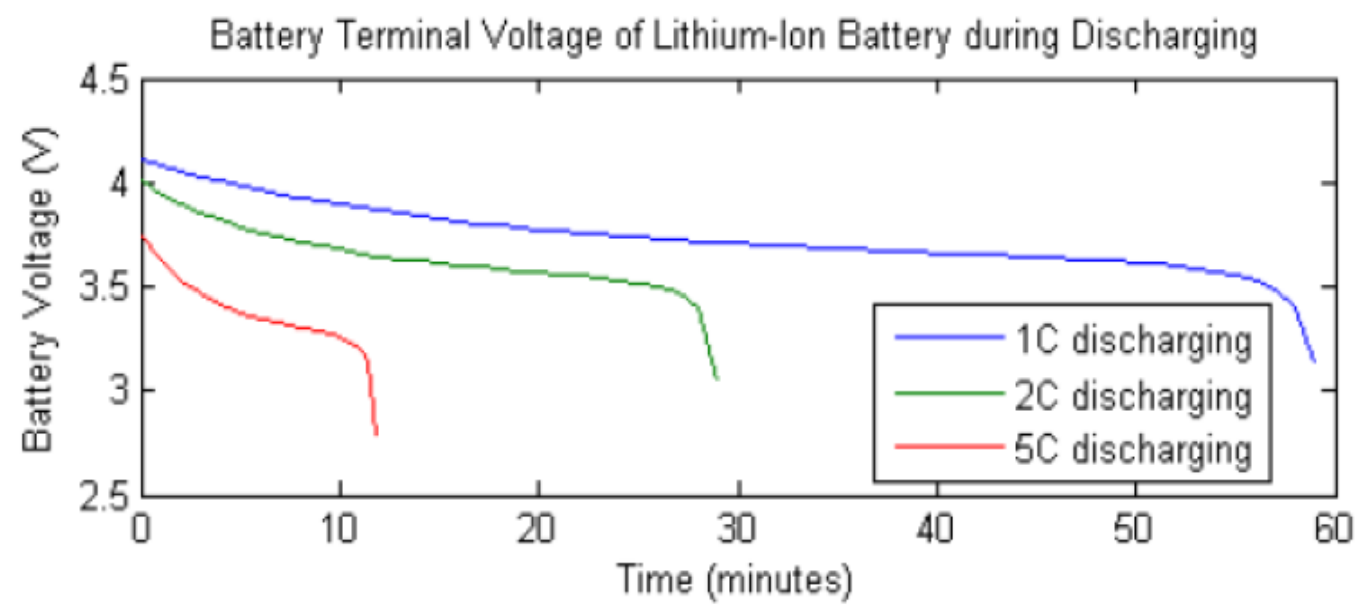

Figure 8. Battery voltage versus time [21].

Figure 9 shows the result of SOC versus time. It has the same characteristics as the curve based on [22]'s studies. SOC decreased with time when the system was running. The percentage of the present battery capacity can be expressed as in Equation 9 [23].

$$
S O C=\frac{Q-Q t}{Q}
$$




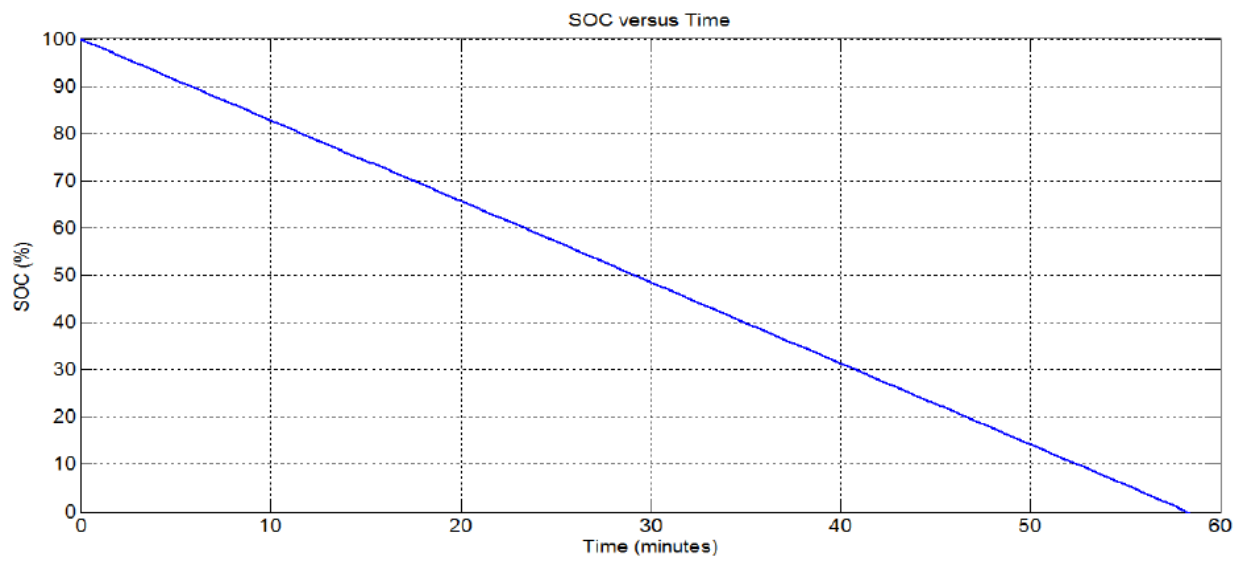

Figure 9. Battery state of charge versus time.

Figure 10 shows that $1 \mathrm{C}$ discharge gave the maximum discharge power approximate to $1300 \mathrm{~W}$ and has the longer discharging time (about $4250 \mathrm{~s}$ ). However, 5C discharge gave the largest discharge power (approximate to $4800 \mathrm{~W}$ ) and has the shortest discharging period (about $3150 \mathrm{~s}$ ). The higher the depth of discharge, the shorter the discharge period [22].

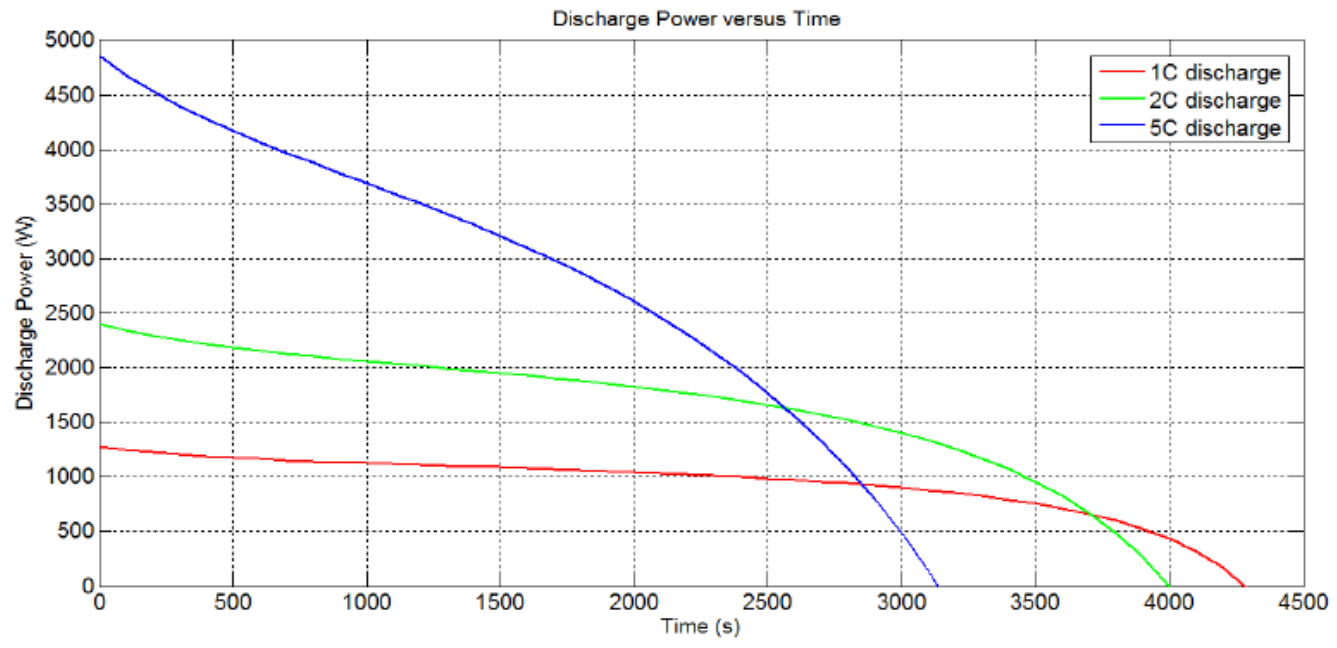

Figure 10. Discharging power versus time.

\section{Optimization using Genetic Alogrithm}

A power load was designed as a reference discharge power for this research [23]. The reference power compromised acceleration, deceleration, and constant speed at 120 seconds. The performance of the developed system is first obtained through tuning by trial-and-error with the PI controller. The $K p$ and $K i$ values were set to 3 . Figure 11 shows the result of power response of the system that was tuned by the PI controller. The system was then optimized by adjusting the PI parameters via GA with the Simulink model with the lower bound of 100 and upper bound of 250. Figure 12 shows the result of power response of the system that was tuned with GA. Meanwhile, Figure 13 shows the minimum error in each iteration. Table 2 shows the objective function at different iteration counts. The result as shown in Figure 11 was the power response-designed PI 
with a population size of 80 . The following response factors were not satisfied from the analysis, where the rise time was 2.9 seconds and the settling time was 5.17 seconds. However, for the GA-designed PI with a population size of 80 as shown in Figure 12, it had some improvement from the analysis of response factors. The rise time was 1.4 seconds and the settling time was 2.5 seconds.

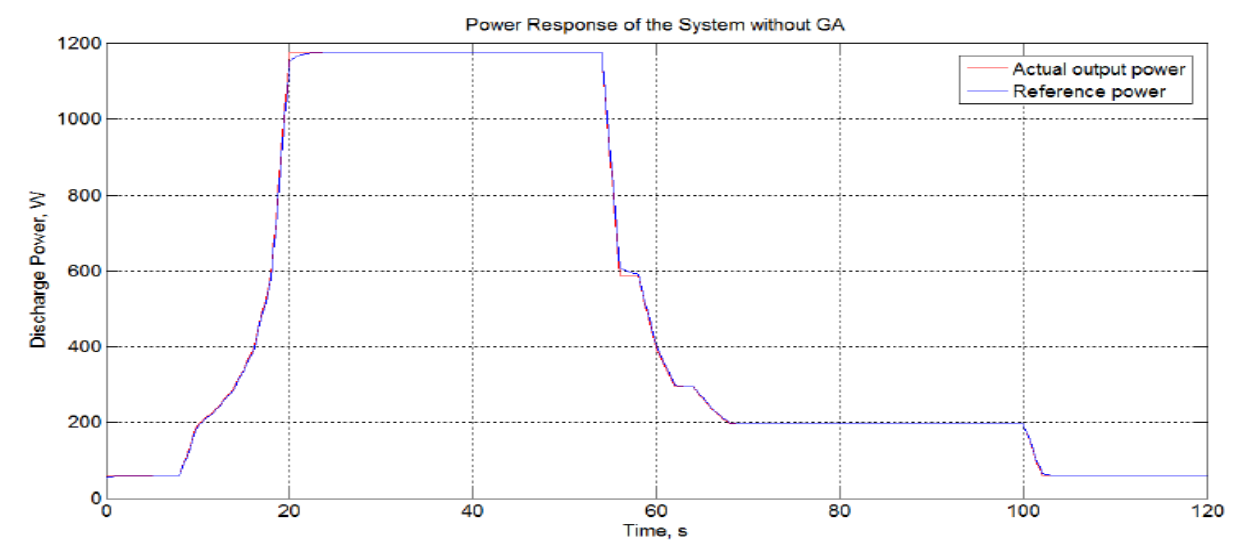

Figure 11. Power response of the system tuned without GA.

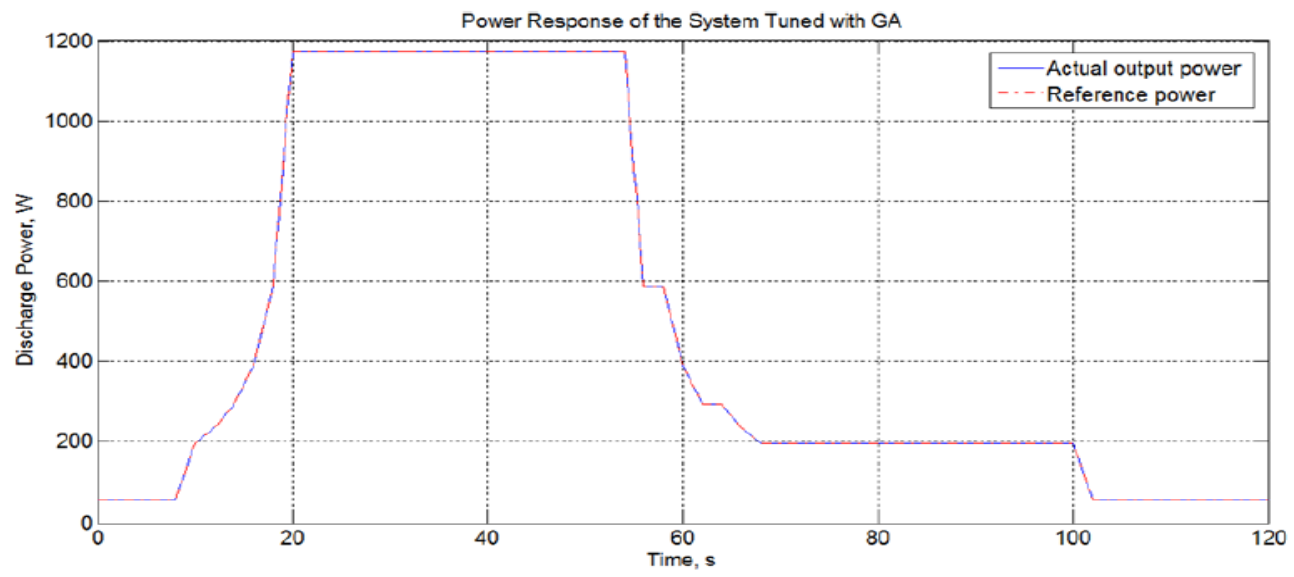

Figure 12. Power response of the system tuned with GA.

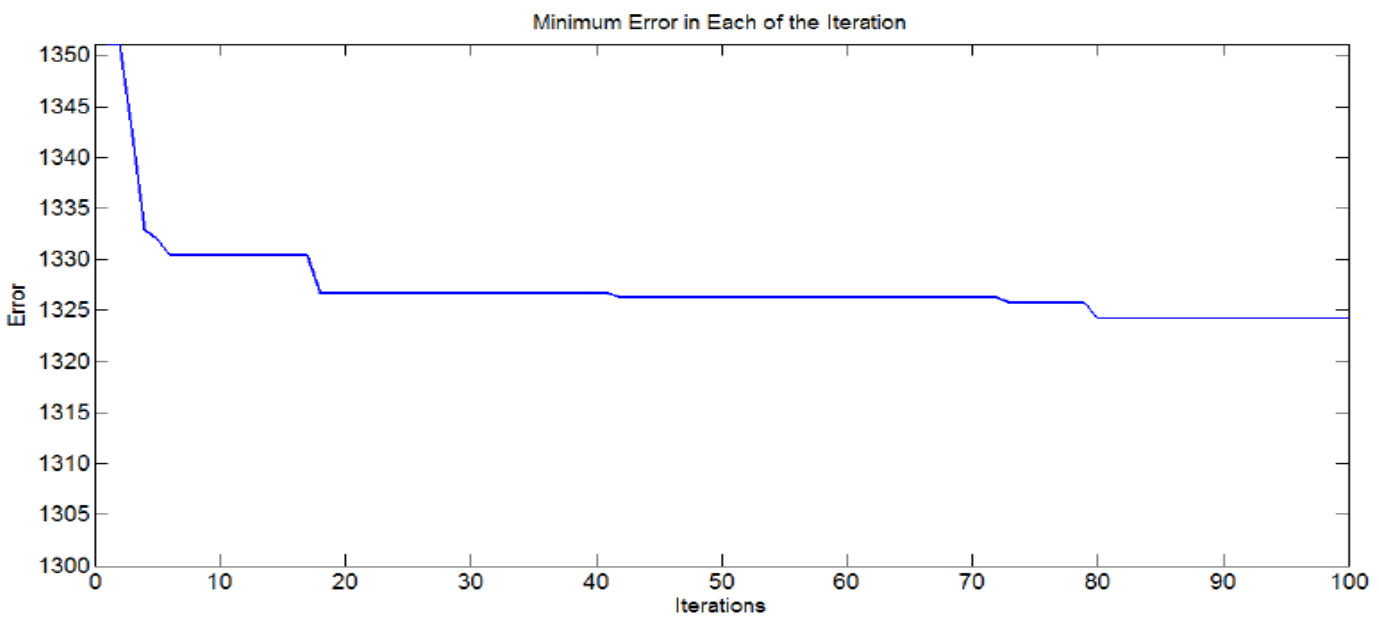

Figure 13. Minimum error in each of the iteration. 


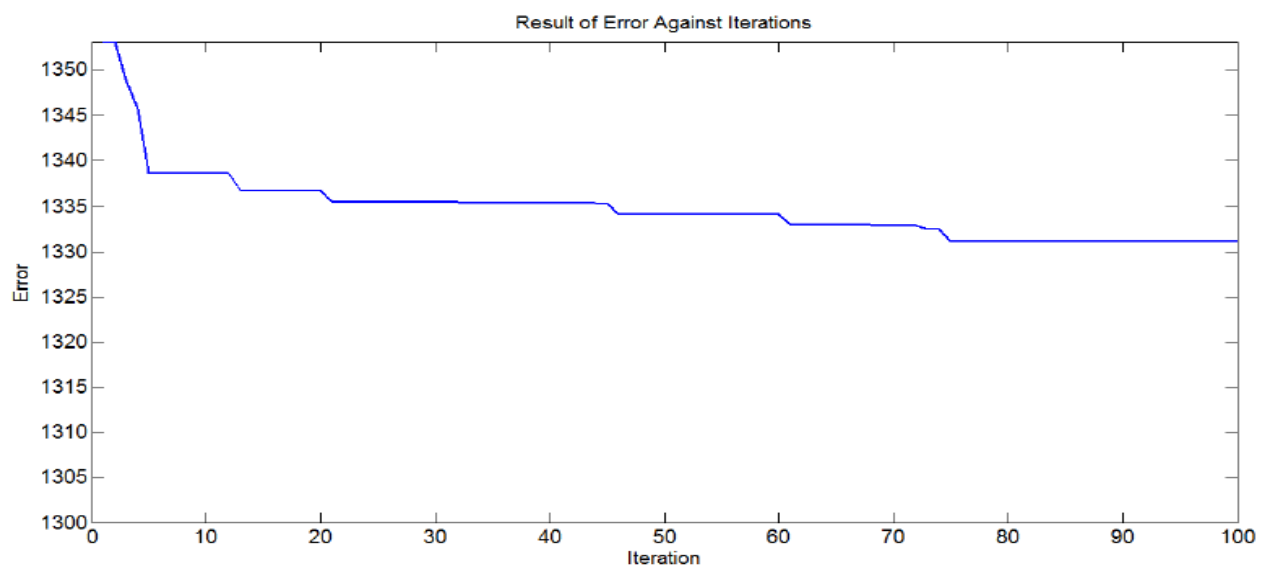

Figure 14. Result of error against iterations.

After the optimization with GA, it showed an improvement on both rise time and settling time. It has an improvement of $51.72 \%$ for rise time and $51.64 \%$ for settling time [23]. In Figure 13 and Table 2, the error continues to be reduced from the first iteration until the last iteration. It showed a steady state error of 1324.23739955 after 80 iterations, which remain constant further. When the power response for the GA-designed PI with a population size of 80 and lower bound of 200 and upper bound 250, the result of power response was almost the same as in Figure 13; but when it was magnified, the errors were still available on it. Figure 14 shows the result of error against iterations and Table 3 shows its objective function at different iteration counts.

Table 2. Objective function at different iteration counts.

\begin{tabular}{cc}
\hline Iteration count & Minimum total error \\
\hline 20 & 1326.65665162 \\
40 & 1326.65665162 \\
60 & 1326.29968620 \\
80 & 1324.23739955 \\
100 & 1324.23739955 \\
\hline
\end{tabular}

Table 3. Objective function at different iteration counts.

\begin{tabular}{cc}
\hline Iteration count & Minimum Total Error \\
\hline 20 & 1336.71354082 \\
40 & 1335.41568238 \\
60 & 1334.16319724 \\
80 & 1331.16988452 \\
100 & 1331.16988452 \\
\hline
\end{tabular}

The rise time from the analysis was 1.93 seconds and the settling time was 3.43 seconds. The improvement of it compared to tuning using PI controller was $33.45 \%$ for rise time and $33.66 \%$ for settling time. However, the setback was that it was inferior when compared to the optimization with lower bound of 100 and upper bound of 250 . Therefore, the optimization with a population of 80 and lower bound of 100 and upper 
bound of 250 was the optimum choice. From Figure 16 and Table 3, the error continues to be reduced from the first iteration until the last iteration. It showed a steady state error of 1331.16988452 after 75 iterations, which remain constant further [24].

\section{CONCLUSIONS}

The paper has shown the development of saft rechargeable lithium ion battery-based PHERB during battery discharge. The model was built based on the parameters, specification, and requirements for the PHERB condition. The validity of the developed model has been verified and the optimal performance of the model has been studied by using the GA-based tuning algorithm of the conventional PI controller. The results show the accuracy of the model developed and it is proven that the GA-based optimization can significantly improve the control system performance of the battery during the discharge condition.

\section{ACKNOWLEDGEMENTS}

The authors would like to be obliged to Universiti Malaysia Terengganu (UMT) for UMT Scholarship, Ministry of Education Malaysia for providing financial assistance under FRGS (59353) grant and School of Ocean Engineering, UMT for all their technical and research support for this work to be successfully complete.

\section{REFERENCES}

[1] Omar S, Arshad N, Yassin I, Fakharuzi M, Ward T. Design and optimization of powertrain system for prototype fuel cell electric vehicle. Journal of Mechanical Engineering and Sciences. 2015;8:1401-13.

[2] Mohd TAT HM, Aziz WMK. Mathematical modeling and simulation of an electric vehicle. Journal of Mechanical Engineering and Sciences. 2015;8:131221.

[3] Salisa A, Walker P, Zhang N, Zhu J. Comparative cost-based analysis of a novel plug-in hybrid electric vehicle with conventional and hybrid electric vehicles. International Journal of Automotive and Mechanical Engineering. 2015;11:226271.

[4] Haezah M, Norbakyah J, Atiq W, Salisa A. A conceptual design of main components sizing for UMT PHEV powertrain. IOP Conference Series: Materials Science and Engineering: IOP Publishing. 2015;012036.

[5] Norbakyah J, Atiq W, Salisa A. Components sizing for PHERB powertrain using ST river driving cycle. IEEE International Conference on Computer, Communications, and Control Technology. 2015;432-6.

[6] Norbakyah JS AW, Salisa AR. Component sizing in PHERB powertrain using PK driving cycle. Journal of Scientific Research and Development. 2015;2:39-42.

[7] Norbakyah JS AW, Salisa AR. Impact component sizing on PHERB powertrain using Tasik Kenyir driving cycle. Australian Journal of Basic and Applied Sciences. 2015;9:56-9.

[8] Norbakyah JS AW, Salisa AR. Powertrain main components sizing of PHERB using KL river driving cycle. ARPN Journal of Engineering and Applied Sciences. 2015;10:8507-10. 
[9] Daud MZ, Kin KZ, Norbakyah J, Salisa A. An optimal electric machine control system design used in plug-in hybrid electric boat. ARPN Journal of Engineering and Applied Sciences. 2006; 10(22):10703-8.

[10] Norbakyah JS AW, Salisa AR. Power requirements for PHERB powertrain. Materials Science and Engineering 2015;100:1-6.

[11] Samadani E, Mastali M, Farhad S, Fraser RA, Fowler M. Li-ion battery performance and degradation in electric vehicles under different usage scenarios. International Journal of Energy Research. 2016;40:379-92.

[12] Panday A, Bansal HO. Energy management strategy for hybrid electric vehicles using genetic algorithm. Journal of Renewable and Sustainable Energy. 2016;8:015701.

[13] Schuster SF, Brand MJ, Berg P, Gleissenberger M, Jossen A. Lithium-ion cell-tocell variation during battery electric vehicle operation. Journal of Power Sources. 2015;297:242-51.

[14] Hoque M, Hannan M, Mohamed A. Voltage equalization control algorithm for monitoring and balancing of series connected lithium-ion battery. Journal of Renewable and Sustainable Energy. 2016;8:025703.

[15] Ni L. Energy storage and management for a small series plug-in hybrid electric vehicle. Thesis, University of Nebraska-Lincoln, USA. 2010.

[16] Wijewardana SW. New dynamic battery model for hybrid vehicles. International Journal of Emerging Technology and Advanced Engineering. 2014;4:622-31.

[17] Hoque M, Hannan M, Mohamed A. Charging and discharging model of lithiumion battery for charge equalization control using particle swarm optimization algorithm. Journal of Renewable and Sustainable Energy. 2016;8:065701.

[18] Ngo PD, Shin YC. Gain estimation of nonlinear dynamic systems modeled by an FBFN and the maximum output scaling factor of a self-tuning PI fuzzy controller. Engineering Applications of Artificial Intelligence. 2015;42:1-15.

[19] Tandon B, Kaur R. Genetic algorithm based parameter tuning of PID controller for composition control system. International Journal of Engineering Science and Technology. 2011;1:6705-11.

[20] Noraini MR, Geraghty J. Genetic algorithm performance with different selection strategies in solving TSP. 2011.

[21] Wu Q, Nielsen AH, Ostergaard J, Cha ST, Marra F, Andersen PB. Modeling of electric vehicles (EVs) for EV grid integration study. 2010.

[22] Chang WY. The state of charge estimating methods for battery: A review. ISRN Applied Mathematics. 2013;2013.

[23] Azidin FA, Hannan MA, Mohamed A. An Energy Management of Light Electric Vehicle. An Energy Management of Light Electric Vehicle. 2013;2:271-6.

[24] Ibrahim S. The PID controller design using genetic algorithm [PhD thesis]: University of Southern Queensland; 2015. 